\title{
К ВОПРОСУ ОТБОРА КОРОВ ПО ТЕХНОЛОГИЧЕСКИМ ПРИЗНАКАМ ВЫМЕНИ
}

\author{
Л.И. Зубкова (фото) \\ к.с.-Х.н., доцент, доцент кафедры зоотехнии \\ ФГБОУ ВО Ярославская ГСХА, г. Ярославль \\ Е.И. Власова \\ магистрант кафедры зоотехнии \\ ФГБОУ ВО Ярославская ГСХА, г. Ярославль \\ специалист по кормам \\ ОАО «Племзавод им. Дзержинского», Ярославская область
}

Молочное скотоводство России в последнее десятилетие XX века претерпело качественные и количественные изменения. Устойчивое обеспечение населения продовольствием является одним из важнейших условий стабильности государства [1].

Потенциал продуктивности скота наращивается за счёт совер-

Технологические признаки вымени, молочная продуктивность коров, полителия, дополнительные соски, воспроизводительные качества

\section{Technological features}

of the udder, milk producing ability of cows, polythelia, additional dugs,

reproductive qualities шенствования отечественных пород и использования мировых генетических ресурсов. Этот процесс начался интенсификацией животноводства в России [1].

В последние годы строятся крупные комплексы и происходит технологическая модернизация молочных ферм, которая основывается на использовании новейшего технологического оборудования, поэтому возникает необходимость в совершенствовании животных по приспособленности к новым условиям содержания и эксплуатации.

Во многих регионах увеличение производства молока обеспечивается исключительно за счёт роста молочной продуктивности коров [2].

Повышение продуктивности скота напрямую связано с совершенствованием молочных признаков животных. При оценке коров, наряду с общей продуктивностью, необходимо учитывать такие ценные индивидуальные качества, как способность длительно поддерживать удои на высоком уровне в течение лактации, отношение удоев за разные отрезки времени [3].

Возможность применения новых технологий в отрасли определяется пригодностью скота к использованию на фермах промышленного типа (пригодностью к машинному доению), улучшению технологических свойств скота, так как на промышленных комплексах и фермах доильные установки рассчитаны на однотипных животных с хорошо развитым, правильной формы выменем и с высокой скоростью молокоотдачи $[4,5]$.

Полителия (полимастия, многососковость) распространена среди крупного рогатого скота молочных пород достаточно широко (рудименты сосков встречаются примерно у $40 \%$ популяции). Рудиментарные (дополнительные) соски представляют собой либо 
эпителиальные выросты, либо в большей или меньшей степени развитые соски с выводным протоком и обособленной железистой тканью. Дополнительные соски, располагаясь на поверхности основных долей вымени, мешают их нормальному развитию и функционированию. Продуцирующие молоко рудименты требуют отдельного выдаивания, что затрудняет процесс машинного доения. Невыдоенные дополнительные соски могут приводить к маститам у коров.

Полителия является морфологическим признаком, определение которого не требует дополнительного оборудования и устанавливается визуально $[6,7,8]$.

Целью нашей работы стало изучение зависимости молочной продуктивности и воспроизводительных качеств коров ярославской породы и ярославско-голштинских помесей в стаде от наличия у них дополнительных сосков.

В задачи исследований вошли: визуальная оценка вымени полителийных коров в зависимости от формы молочной железы и расположения рудиментарных сосков; изучение зависимости между молочной продуктивностью и воспроизводительными качествами коров и наличием дополнительных сосков, расчёт экономической эффективности производства молока коров, не имеющих полителии.

\section{Материал и методика исследований}

Объекты исследований - коровы ярославской породы и помеси с голштинской породой разной кровности, находящиеся в стаде ОАО «Племзавод им. Дзержинского» Ярославского района. Нами было исследовано 307 голов коров, при глазомерной оценке стада выявлено 60 голов с полителией и 247 - не имеющих дополнительных сосков. К выборке животных с рудиментарными сосками были подобраны сверстни- цы по возрасту, возрасту 1-го отёла и количеству законченных лактаций.

Методы исследований - общезоотехнические, с биометрической обработкой количественных показателей на ПК в программе Microsoft Excel.

\section{Результаты исследований}

Одним из морфологических признаков вымени, который в известной степени препятствует эффективности машинного доения, является наличие добавочных сосков (полителия). Располагаются они преимущественно на задних долях вымени, но могут находиться между задними и передними нормальными сосками. Располагаясь на поверхности основных долей вымени, они мешают их нормальному развитию и функционированию, ухудшая тем самым молокоотдачу. Кроме того, функционирующие добавочные соски приходится выдаивать отдельно, что существенно затрудняет машинное доение. Замечено, что добавочные соски с собственной железой часто после отёла воспаляются и становятся очагом инфекции для здоровых четвертей вымени.

При глазомерной оценке вымени 307 учтённых коров дополнительные соски имели 19,54\% животных, т.е. 60 голов (табл. 1).

При подборе коров для машинного доения важное значение придаётся форме, размерам и расположениям сосков. Определённая стандартизация по этим признакам позволяет повысить эффективность доения аппаратами. Из исследуемого поголовья полителия наблюдается у 29 голов ярославской породы и 31 - ярославско-голштинской помеси. 32 полителийные коровы, или 53,3\%, имели по одному добавочному соску и 28 коров, или 46,7\%, - по два.

Дополнительные соски расположены у 54 коров (90\%) позади задних сосков задней половины

Таблица 1 - Характеристика вымени коров по месту расположения дополнительных сосков

\begin{tabular}{|c|c|c|c|c|c|c|c|c|c|c|}
\hline \multirow{4}{*}{ Форма вымени } & \multicolumn{10}{|c|}{ Коровы с полителией } \\
\hline & \multirow{2}{*}{\multicolumn{2}{|c|}{$\begin{array}{c}\text { Ярославская } \\
\text { порода }\end{array}$}} & \multirow{2}{*}{\multicolumn{2}{|c|}{$\begin{array}{c}\text { Ярославско- } \\
\text { голштинские } \\
\text { помеси }\end{array}$}} & \multirow{2}{*}{\multicolumn{2}{|c|}{$\begin{array}{c}\text { Кол-во добавоч- } \\
\text { ных сосков на } \\
\text { вымени свыше } \\
4-x\end{array}$}} & \multicolumn{4}{|c|}{ Расположение добавочных сосков } \\
\hline & & & & & & & \multicolumn{2}{|c|}{$\begin{array}{c}\text { позади задних } \\
\text { сосков }\end{array}$} & \multicolumn{2}{|c|}{$\begin{array}{c}\text { между задними } \\
\text { и передними }\end{array}$} \\
\hline & гол. & $\%$ & гол. & $\%$ & 1 & 2 & гол. & $\%$ & гол. & $\%$ \\
\hline Ваннообразная & 4 & 13,8 & 2 & 6,4 & 4 & 2 & 6 & 11,1 & - & - \\
\hline Чашеобразная & 5 & 17,2 & 2 & 6,4 & 3 & 4 & 6 & 11,1 & 1 & 16,7 \\
\hline Округлая & 20 & 69,0 & 27 & 72,2 & 25 & 22 & 42 & 77,8 & 5 & 83,3 \\
\hline Итого & 29 & 100,0 & 31 & 100,0 & 32 & 28 & 54 & 100,0 & 6 & 100,0 \\
\hline
\end{tabular}


Продолжение таблицы 1

\begin{tabular}{|c|c|c|c|c|c|c|c|c|c|c|}
\hline \multirow{4}{*}{ Форма вымени } & \multirow{2}{*}{\multicolumn{4}{|c|}{$\begin{array}{c}\text { Коровы с полителией } \\
\text { Расположение задних } \\
\text { добавочных сосков }\end{array}$}} & \multicolumn{6}{|c|}{ Коровы-сверстницы } \\
\hline & & & & & \multirow{2}{*}{\multicolumn{2}{|c|}{$\begin{array}{c}\text { Расположение до- } \\
\text { бавочных сосков } \\
\text { на левой и правой } \\
\text { половине одно- } \\
\text { временно }\end{array}$}} & \multirow{2}{*}{\multicolumn{2}{|c|}{$\begin{array}{c}\text { Ярославская } \\
\text { порода }\end{array}$}} & \multirow{2}{*}{\multicolumn{2}{|c|}{$\begin{array}{c}\text { Ярославско- } \\
\text { голштинские } \\
\text { помеси }\end{array}$}} \\
\hline & \multicolumn{2}{|c|}{$\begin{array}{c}\text { на левой } \\
\text { половине }\end{array}$} & \multicolumn{2}{|c|}{$\begin{array}{c}\text { на правой } \\
\text { половине }\end{array}$} & & & & & & \\
\hline & гол. & $\%$ & гол. & $\%$ & гол. & $\%$ & гол. & $\%$ & гол. & $\%$ \\
\hline Ваннообразная & 1 & 6,7 & 3 & 16,6 & 2 & 7,4 & - & - & 5 & 13,2 \\
\hline Чашеобразная & 2 & 13,3 & 1 & 5,6 & 4 & 14,8 & 4 & 18,2 & 6 & 15,8 \\
\hline Округлая & 12 & 80 & 14 & 77,8 & 21 & 77,8 & 18 & 81,8 & 27 & 71,0 \\
\hline Итого & 15 & 100,0 & 18 & 100,0 & 27 & 100,0 & 22 & 100,0 & 38 & 100,0 \\
\hline
\end{tabular}

вымени, у остальных 6 (10\%) - между задними и передними.

Наличие добавочных сосков на левой и правой половине вымени одновременно отмечено у 27 коров (45\%), на правой половине - у 18 коров (30\%), на левой половине - у 15 коров (25\%). Наибольшая встречаемость полителии наблюдается у коров с округлым выменем (47 гол., или 78,3\%), наименьшая - у коров с ваннообразной формой вымени (6 гол., или 10\%).

Для анализа физиологических свойств вымени в исследования взято 49 коров с дополнительными сосками (т.к. у остальных 11 незаконченная 1-я лактация и не произведена оценка свойств вымени и молокоотдачи) и 49 - без полителии.

Важными признаками в подборе коров для машинного доения являются не только форма вымени, но функциональные, качественные свойства молочной железы.

Нами установлено, что суточный удой коровсверстниц в среднем превышает удой за сутки коров с добавочными сосками ярославской породы на 2,1 кг, ярославско-голштинских помесей - на 3,2 кг; скорость молокоотдачи также выше в груп- пе коров-сверстниц на 0,12 кг/мин. и 0,11 кг/мин. соответственно.

Во многих опытах доказано, что высокие показатели оценки вымени соответствуют высокой продуктивности.

Из таблицы 3 видно, что по первой лактации различия по продолжительности лактации в полителийных группах и без рудиментов сосков незначительны, разница по ярославской породе и ярославско-голштинским помесям не превышает 10 дней. Коровы с полителией по ярославской породе по удою за 305 дней первой лактации уступают животным без неё на 36,4 кг $(0,7 \%)$, по ярославско-голштинским помесям удой за 305 дней выше в группе без добавочных сосков на 412,8 кг (7\%). Анализ жирномолочности ярославских коров показывает, что первотёлки с полителией по количеству молочного жира превышают тот же показатель у коров без дополнительных сосков на 0,8 кг (0,3\%), а в группе ярославско-голштинских помесей первотёлки без полителии превосходят сверстниц на 22,1 кг (8,4\%). У полителийных коров ярославской породы и у помесей МДЖ и МДБ выше, чем у

Таблица 2 - Оценка свойств вымени коров с добавочными сосками и нормальным выменем

\begin{tabular}{|l|c|c|c|c|}
\hline \multirow{2}{*}{ Признак } & \multicolumn{2}{|c|}{ Полителийная группа } & \multicolumn{2}{c|}{ Группа коров-сверстниц } \\
\cline { 2 - 5 } & $\begin{array}{c}\text { Ярославская } \\
\text { порода }(\mathrm{n}=24)\end{array}$ & $\begin{array}{c}\text { Ярославско-голштин- } \\
\text { Ские помеси }(\mathrm{n}=25)\end{array}$ & $\begin{array}{c}\text { Ярославская } \\
\text { порода }(\mathrm{n}=20)\end{array}$ & $\begin{array}{c}\text { Ярославско-голштин- } \\
\text { ские помеси }(\mathrm{n}=29)\end{array}$ \\
\hline Суточный удой, кг & 19,5 & 20,7 & 21,6 & 12,9 \\
\hline Время доения, мин. & 11,2 & 11,5 & 1,6 & 1,4 \\
\hline $\begin{array}{l}\text { Скорость молокоотдачи, } \\
\text { кг/мин. }\end{array}$ & 1,73 & 1,79 & 10 & 10 \\
\hline $\begin{array}{l}\text { Балл за скорость } \\
\text { молокоотдачи }\end{array}$ & 10 & 10 & 1,90 \\
\hline
\end{tabular}


Таблица 3 - Показатели изменчивости признаков продуктивности полителийных коров и их сверстниц по 1-й лактации

\begin{tabular}{|c|c|c|c|c|c|c|}
\hline \multirow{3}{*}{ Признак } & \multicolumn{3}{|c|}{ Ярославская порода } & \multicolumn{3}{|c|}{ Ярославско-голштинские помеси } \\
\hline & \multicolumn{2}{|c|}{$M \pm m$} & \multirow{2}{*}{$\begin{array}{l}\text { Разница } \\
(+/-)\end{array}$} & \multicolumn{2}{|c|}{$M \pm m$} & \multirow{2}{*}{$\begin{array}{c}\text { Разница } \\
(+/-)\end{array}$} \\
\hline & $\begin{array}{c}\text { С полителией } \\
(\mathrm{n}=24)\end{array}$ & $\begin{array}{c}\text { Без полителии } \\
(n=20)\end{array}$ & & $\begin{array}{c}\text { С полителией } \\
(\mathrm{n}=25)\end{array}$ & $\begin{array}{c}\text { Без полителии } \\
(n=29)\end{array}$ & \\
\hline $\begin{array}{l}\text { Количество } \\
\text { дойных дней, дн. }\end{array}$ & $317 \pm 14$ & $307 \pm 9$ & -10 & $339 \pm 13$ & $342 \pm 16$ & +3 \\
\hline Фактический надой, кг & $5160,0 \pm 316,3$ & $5125,2 \pm 298,3$ & $-34,8$ & $6118,3 \pm 363,4$ & $6615,8 \pm 325,3$ & $+497,5$ \\
\hline Удой за 305 дней, кг & $4928,4 \pm 246,3$ & $4964,8 \pm 276,3$ & $+36,4$ & $5528,3 \pm 244,7$ & $5941,1 \pm 235,6$ & $+412,8$ \\
\hline мдж, \% & $4,73 \pm 0,12$ & $4,63 \pm 0,16$ & $-0,1$ & $4,39 \pm 0,13$ & $4,37 \pm 0,09$ & $-0,02$ \\
\hline $\begin{array}{l}\text { Количество молочного } \\
\text { жира, кг }\end{array}$ & $233,6 \pm 12,8$ & $232,8 \pm 16,7$ & $-0,8$ & $242,2 \pm 12,2$ & $264,3 \pm 11,0$ & $+22,1$ \\
\hline МДБ, \% & $3,21 \pm 0,03$ & $3,19 \pm 0,03$ & $-0,02$ & $3,14 \pm 0,04$ & $3,13 \pm 0,04$ & $-0,01$ \\
\hline $\begin{array}{l}\text { Продуктивность при 4\% } \\
\text { жирности, кг }\end{array}$ & $6060,5 \pm 374,8$ & $6017,0 \pm 447,0$ & $-43,5$ & $6691,3 \pm 456,1$ & $7205,2 \pm 373,1$ & $+513,9$ \\
\hline Живая масса, кг & $470,8 \pm 5,2$ & $477,3 \pm 5,8$ & $+6,5$ & $480,4 \pm 3,2$ & $491,5 \pm 5,9$ & $+11,1$ \\
\hline $\begin{array}{l}\text { Коэффициент } \\
\text { молочности, кг }\end{array}$ & $1103,6 \pm 74,5$ & $1069,3 \pm 59,2$ & $-34,3$ & $1271,6 \pm 74,5$ & $1353,8 \pm 72,5$ & $+82,2$ \\
\hline Суточный удой, кг & $19,5 \pm 0,9$ & $21,6 \pm 1,2$ & $+2,1$ & $20,7 \pm 1,1$ & $23,9 \pm 1,1^{*}$ & $+3,2$ \\
\hline $\begin{array}{l}\text { Скорость молокоотдачи, } \\
\text { кг/мин. }\end{array}$ & $1,73 \pm 0,05$ & $1,85 \pm 0,07$ & $+0,12$ & $1,79 \pm 0,06$ & $1,90 \pm 0,05$ & $+0,11$ \\
\hline
\end{tabular}

* - значение изменчивости признаков достоверно при $\mathrm{P} \geq 0,95$.

первотёлок без рудиментов сосков. Живая масса выше у особей без дополнительных сосков, она составила по ярославской породе 477,3 кг, по ярославско-голштинским помесям - 491,5 кг. Суточный удой и скорость молокоотдачи выше у коров-сверстниц ярославской породы и помесей по голштинской породе без полителии на 2,1 и 3,2 кг и 0,12 и 0,11 кг/мин. соответственно. Вычисленная разница по суточному удою в помесной группе статистически достоверна по 1 порогу $(P \geq 0,95)$.
В наших исследованиях (табл. 4) по 1-й лактации возраст 1-го отёла по ярославской породе ниже в группе с полителией на 20 дней (2,3\%), что достоверно по 1 порогу, по ярославско-голштинским помесям в группе без добавочных сосков на 10 дней (1,2\%).

Сервис-период у коров ярославской породы без полителии входит в норму и составил 82 дня, что на 15 дней (18,3\%) меньше, чем в полителийной группе. Различие между сервис-периодами в помесной группе составило 6 дней $(4,8 \%)$.

Таблица 4 - Показатели изменчивости воспроизводительных качеств коров с полителией и группы сверстниц по 1-й лактации в зависимости от породной принадлежности

\begin{tabular}{|c|c|c|c|c|c|c|}
\hline \multirow{3}{*}{ Признак } & \multicolumn{3}{|c|}{ Ярославская порода } & \multicolumn{3}{|c|}{ Ярославско-голштинские помеси } \\
\hline & \multicolumn{2}{|c|}{$M \pm m$} & \multirow{2}{*}{$\begin{array}{c}\text { Разница } \\
(+/-)\end{array}$} & \multicolumn{2}{|c|}{$M \pm m$} & \multirow{2}{*}{$\begin{array}{c}\text { Разница } \\
(+/-)\end{array}$} \\
\hline & $\begin{array}{c}\text { С полителией } \\
(\mathrm{n}=24)\end{array}$ & $\begin{array}{c}\text { Без полителии } \\
\quad(\mathrm{n}=20)\end{array}$ & & $\begin{array}{c}\text { С полителией } \\
(\mathrm{n}=25)\end{array}$ & $\begin{array}{c}\text { Без полителии } \\
\quad(\mathrm{n}=29)\end{array}$ & \\
\hline Возраст 1-го отёла, дн. & $820 \pm 16$ & $887 \pm 23^{*}$ & +20 & $838 \pm 26$ & $828 \pm 19$ & -10 \\
\hline Сервис-период, дн. & $97 \pm 16$ & $82 \pm 8$ & -15 & $120 \pm 13$ & $126 \pm 18$ & +6 \\
\hline МОП, дн. & $380 \pm 16$ & $362 \pm 8$ & -18 & $404 \pm 13$ & $407 \pm 18$ & +3 \\
\hline KBC & $0,99 \pm 0,03$ & $1,02 \pm 0,02$ & $+0,03$ & $0,93 \pm 0,03$ & $0,94 \pm 0,03$ & $+0,01$ \\
\hline
\end{tabular}

* - значение изменчивости признаков достоверно при $\mathrm{P} \geq 0,95$. 
МОП по ярославской породе выше в группе с дополнительными сосками на 18 дней (5\%), по помесям у коров с нормальным выменем - на 3 дня (0,8\%).

КВС выше в группах без полителии.

При расчёте экономической эффективности валовое производство молока базисной $(3,4 \%)$ жирности от коров с нормальным выменем превышает показатели полителийной группы коров на $6,6 \%$.

Уровень рентабельности полителийных особей ниже на 12,8\%, чем тот же показатель у дойных коров с нормальным выменем.

Коровы с добавочными сосками менее рентабельны, чем коровы с нормальным выменем. То есть если их заменить животными без рудиментарных сосков вымени, то выручка от производ- ства и реализации молока возрастёт, что положительно отразится на экономических показателях хозяйства.

\section{Выводы}

1. Коровы с нормальным выменем по удою за 305 дней первой лактации превышают показатели своих полителийных сверстниц на 5,56\% (308 кг).

2. Скорость молокоотдачи у коров-сверстниц выше на 6,38\% (0,12 кг/мин.).

3. Более высокая экономическая эффективность производства молока наблюдается при использовании животных без рудиментарных сосков. Уровень рентабельности полителийных особей ниже на 12,8\%, чем тот же показатель у дойных коров с нормальным выменем.

\section{Лumepamypa}

1. Тамарова, Р.В. Продолжительность хозяйственного использования и пожизненная продуктивность голштинских коров в селекции Канады в ОАО племзавод «Михайловское» Ярославской области [Текст] / Р.В. Тамарова // Вестник АПК Верхневолжья. - 2018. - № 3 (43). - С. 36-41.

2. Филинская, О.В. Продуктивные качества коров разных генотипов [Текст] / О.В. Филинская, Л.Ю. Герасимова // Вестник АПК Верхневолжья. - 2019. - № 2 (46). - С. 32-36.

3. Филинская, О.В. Характеристика показателей лактации коров ярославской породы [Текст] / О.В. Филинская, О.В. Ивачкина // Вестник АПК Верхневолжья. - 2017. - № 4 (40). - С. 12-17.

4. Зубкова, Л.И. Воспроизводство крупного рогатого скота [Текст]: монография / Л.И. Зубкова, Л.П. Москаленко, В.Я. Гангур. - Ярославль: Изд-во ФГБОУ ВПО «Ярославская ГСХА», 2012. - 150 с.

5. Калмыкова, О.А. Полителия в этиологии мастита коров [Текст] / О.А. Калмыкова, И.П. Прохоров // Наука и образование в 21 веке: сб. науч. тр. по материалам Международ. науч.-практ. конф.: в 34 частях. Тамбов: Изд-во ООО «Консалтинговая компания Юком», 2013. - С. 55-57.

6. Комаров, В. Новые способы и средства диагностик, терапии и профилактики мастита у коров [Текст] / В. Комаров // Вестник ОрелГАУ. - 2015. - № 5 (56). - С. 82-86.

7. Кондрашкова, И.С. Взаимосвязь морфофункциональных свойств вымени с молочной продуктивностью [Текст] / И.С. Кондрашкова, Е.В. Трифанова // Аграрная наука - сельскому хозяйству: сб. статей: в 3 книгах. - Алтайский государственный аграрный университет, 2017. - С. 138-140.

8. Максимович, Н.В. Взаимосвязь мастита коров с состоянием вымени [Текст] / Н.В. Максимович, Н.А. Кузнецов // Актуальные проблемы интенсивного развития животноводства. - 2012. - № 15-2. C. 233-239.

\section{References}

1.Tamarova, R.V. Prodolzhitel'nost' hozjajstvennogo ispol'zovanija i pozhiznennaja produktivnost' golshtinskih korov v selekcii Kanady v OAO plemzavod «Mihajlovskoe» Jaroslavskoj oblasti [Tekst] / R.V. Tamarova // Vestnik APK Verhnevolzh'ja. - 2018. - № 3 (43). - S. 36-41.

2. Filinskaya, O.V. Produktivnye kachestva korov raznyh genotipov [Tekst] / O.V. Filinskaya, L.Yu. Gerasimova // Vestnik APK Verhnevolzh'ja. - 2019. - № 2 (46). - S. 32-36.

3. Filinskaya, O.V. Harakteristika pokazatelej laktacii korov jaroslavskoj porody [Tekst] / O.V. Filinskaya, O.V. Ivachkina // Vestnik APK Verhnevolzh'ja. - 2017. - № 4 (40). - S. 12-17.

4.Zubkova, L.I. Vosproizvodstvo krupnogo rogatogo skota [Tekst]: monografija / L.I. Zubkova, L.P. Moskalenko, V.Ya. Gangur. - Jaroslavl': Izd-vo FGBOU VPO «Jaroslavskaja GSHA», 2012. - 150 s.

5. Kalmykova, O.A. Politelija v jetiologii mastita korov [Tekst] / O.A. Kalmykova, I.P. Prokhorov // Nauka i obrazovanie $v 21$ veke: sb. nauch. tr. po materialam Mezhdunarod. nauch.-prakt. konf.: $v 34$ chastjah. - Tambov: Izd-vo OOO «Konsaltingovaja kompanija Jukom», 2013. - S. 55-57. 
6. Komarov, V. Novye sposoby i sredstva diagnostik, terapii i profilaktiki mastita u korov [Tekst] / V. Komarov //Vestnik OrelGAU. - 2015. - № 5 (56). - S. 82-86.

7. Kondrashkova, I.S.Vzaimosvjaz' morfofunkcional'nyh svojstv vymeni s molochnoj produktivnost'ju [Tekst] / I.S. Kondrashkova, E.V. Trifanova // Agrarnaja nauka - sel'skomu hozjajstvu: sb. statej: v 3 knigah. - Altajskij gosudarstvennyj agrarnyj universitet, 2017. - S. 138-140.

8. Maksimovich, N.V. Vzaimosvjaz' mastita korov s sostojaniem vymeni [Tekst] / N.V. Maksimovich, N.A. Kuznetsov // Aktual'nye problemy intensivnogo razvitija zhivotnovodstva. - 2012. - № 15-2. - S. 233-239.

\section{ОБЫЯВЛЕНИЕ}

В издательстве ФГБОУ ВО Ярославская ГСХА в 2019 году вышло учебное пособие, получившее гриф Федерального УМО по сельскому, лесному и рыбному хозяйству для обучающихся по направлению подготовки 35.03 .06 «Агроинженерия»

(профиль «Электрооборудование и электротехнологии в АПК») «ЛИНЕЙНЫЕ ЭЛЕКТРИЧЕСКИЕ ЦЕПИ» Авторы: В.В. МОРОЗОВ, П.С. ОРЛОВ, В.В. ШМИГЕЛЬ

УЧЕБНОЕ ПОСОБИЕ СОДЕРЖИТ СВЕДЕНИЯ, НЕОБХОДИМЫЕ ДЛЯ ФОРМИРОВАНИЯ ПРОФЕССИОНАЛЬНЫХ КОМПЕТЕНЦИЙ ПРИ ПОДГОТОВКЕ БАКАЛАВРОВ ПО НАПРАВЛЕНИЮ «АГРОИНЖЕНЕРИЯ», И РЕКОМЕНДУЕТСЯ НАУЧНО-МЕТОДИЧЕСКИМ СОВЕТОМ ПО ТЕХНОЛОГИЯМ, СРЕДСТВАМ МЕХАНИЗАЦИИ И ЭНЕРГЕТИЧЕСКОМУ ОБОРУДОВАНИЮ В СЕЛЬСКОМ ХОЗЯЙСТВЕ ФЕДЕРАЛЬНОГО УМО

ПО СЕЛЬСКОМУ, ЛЕСНОМУ И РЫБНОМУ ХОЗЯЙСТВУ ДЛЯ ИСПОЛЬЗОВАНИЯ В УЧЕБНОМ ПРОЦЕССЕ.

В учебном пособии представлены курс лекций и практические работы по разделу «Линейные электрические цепи» дисциплины «Теоретические основы электротехники» с контрольными вопросами и задачами для самопроверки обучающихся.

УДК 621.317; ББК 31.21; ISВN 978-5-98914-201-9; 334 СТР.

ПО ВОПРОСАМ ПРИОБРЕТЕНИЯ ОБРАЩАТЬСЯ ПО АДРЕСУ: 150042, г. Ярославль, Тутаевское шоссе, 58, ФГБОУ ВО Ярославская ГСХА e-mail: e.bogoslovskaya@yarcx.ru 